\title{
Fibroblasts adhesion on six different titanium surfaces: An in vitro experimental study
}

\author{
Gehrke SA*, Pérez-Díaz L**, Shibli JA ${ }^{\star \star *}$, Blay $A^{\star \star *}$, Samy $T^{\star \star *}$.
}

*Biotecnos - Technology and Science, Montevideo, Uruguay; **Universidad de la Republica, Montevideo, Uruguay; ${ }^{* *}$ Universidade de Guarulhos, Gurarulhos, Brazil.

\section{Abstract}

Objectives: The aim of this work was to evaluate if different titanium surface treatments could influence cell growth on these surfaces. For this purpose, we evaluated the surface topography of the discs through SEM and roughness parameters values using profilometry analysis. Then, we assayed an in vitro experimental study using a fibroblast like cell line derived from Kidney of African green monkey to analyze viability of these cells growing on six tested surfaces.

Materials and Methods: For this study 90 titanium disks with 6 different method of surface treatments ( $n=15$ per group) were produced and used: method $\mathrm{mA}$ (machined surface), method mB (Sandblasting etching using aluminum oxide), method $\mathrm{mC}$ (Sandblasting etching using titanium oxide), $\mathrm{mD}$ (triple acid conditioning), method $\mathrm{mE}$ (laser treatment) and method $\mathrm{mF}$ (surface produced by titanium powder sintering process). All disks were decontaminated, packaged and sterilized with the same conditions used for the commercialization of implantable materials. The surface of different discs was analyzed using an optical laser profilometer for surface roughness characterization and SEM analysis. To evaluate cell adhesion on different disc surfaces, a fibroblast cell line derived from monkey kidney (VERO) was in vitro cultured used treated discs as support cell viability assays were performed to compare growth of fibroblastic cells on the different surfaces.

Results: Data here presented revealed a significantly higher mitochondrial activity in cells growing on $\mathrm{mF}$ discs.

Conclusions: Our analysis showed that matrix space and time of laser application during titanium disc surface treatment affect differentially cell viability since a higher percentage of viable cell was observed while using method $\mathrm{mF}$ in comparison with the others methods evaluated.

\section{Background and Aim}

Several studies on cell adhesion and dissemination have been carried out on surfaces with different topographies in the last 50 years. This topographical surficial characteristics and properties of materials can induce different cell reactions such as cell adhesion, spreading, motility, proliferation and death. Although there is no established consensus as to the optimum surface area for better and faster cell adhesion to titanium, it has been reported that surfaces with exaggerated roughness do not achieve satisfactory results in relation to the speed and quality of adhesion of fibroblasts.

\section{Methods and Materials}

For this study 90 titanium disks with 6 different method of surface treatments $(n=$ 15 per group) were produced and used: method $\mathrm{mA}$ (machined surface), method $\mathrm{mB}$ (Sandblasting etching using aluminum oxide), (Sandblasting etching using aluminum oxide), titanium oxide), $\mathrm{mD}$ (triple acid conditioning), method $\mathrm{mE}$ (laser treatment) and method $\mathrm{mF}$ (surface produced by titanium powder sintering process). All disks were decontaminated, packaged and sterilized with the same conditions used for the commercialization of implantable materials. The surface of different discs was anazed Thing ance of different using an optical laser proflometer for surface roughness characterization and SEM analysis. To evaluate cell adhesion on different disc surfaces, a fibroblast cell line derived from monkey kidney (VERO) was in vitro cultured used treated discs as support cell viability assays were performed to compare growth of fibroblastic cells on the different surfaces.

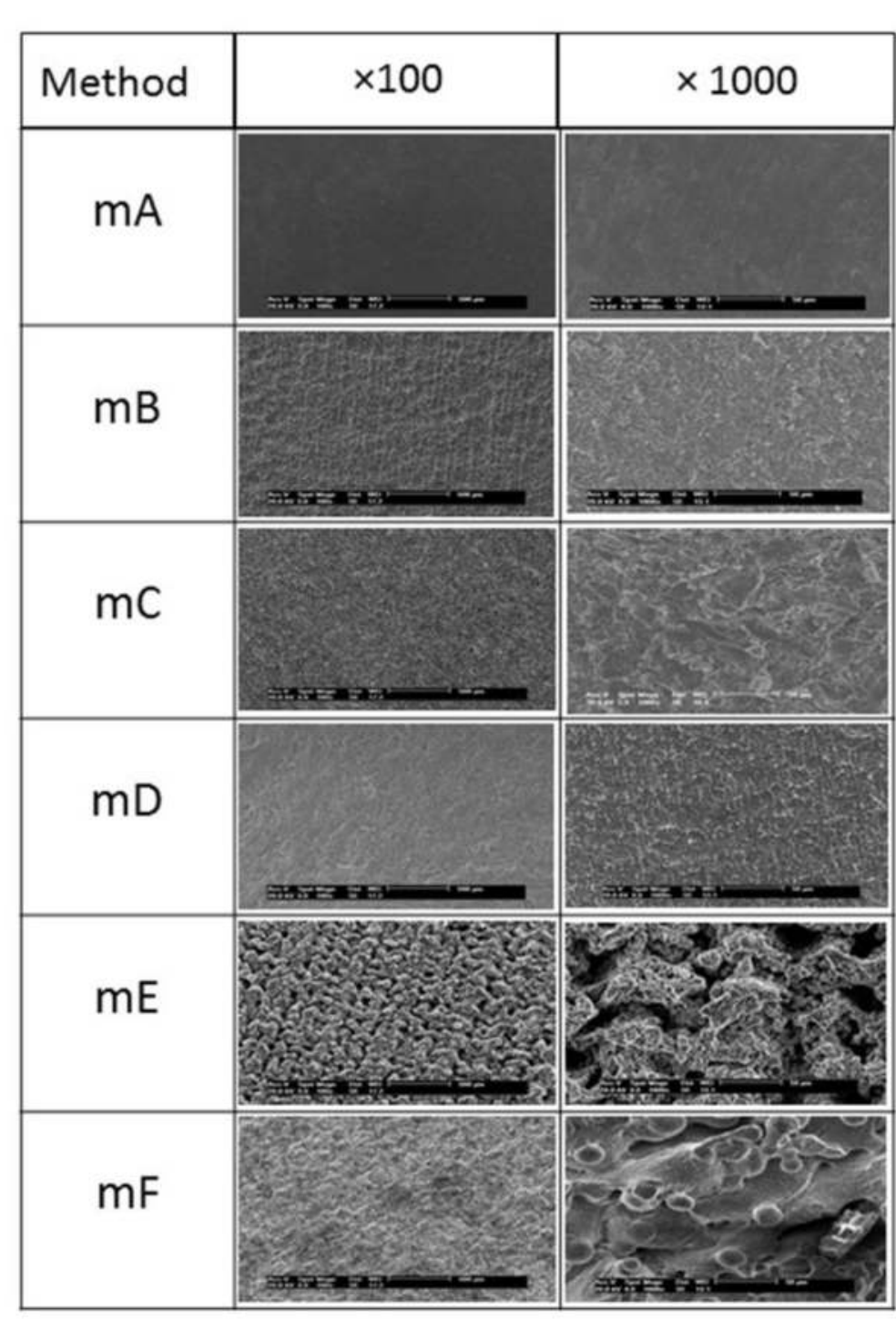

The surface of different discs was analyzed using an optical laser profilometer for surface roughness characterization and SEM analysis. The scheme shown in the figure on the side, of the rugosity parameters evaluate Rt = measuring the high variation of the Valleys; $\mathrm{Ra}=$ the absolute values of all profile points; $\mathrm{Rq}=$ vello the value of the absolute heights of points; and, $\mathrm{Rz}_{2}$ the value of the absolute heights of the five highes peaks and the depths of the five deepest valleys.

\section{Results}

\section{Profilometry and SEM of the disc surface:}

To evaluate topographic characteristics of different surfaces, SEM and profilometry analysis were performed. For SEM analysis, images of discs were obtained at $\times 100$ and $\times 1000$ based on secondary electrons (SEs). The SEM images show different configurations of the studied surfaces. For disc surfaces treated with methods $\mathrm{mA}, \mathrm{mB}, \mathrm{mC}$ and $\mathrm{mD}$ less pronounced rugosities were observed. Nevertheless, disc surfaces treated with $\mathrm{mE}$ and $\mathrm{mF}$ method displayed a deeper pronounced surface. For disc $\mathrm{mF}$ treated, small spherical protuberances appear emerging from the sulcus.

Roughness of different surfaces was analyzed by profilometry using a optical laser Profilometer to analyze the topography. The obtained values for the roughness parameters included in this study ( $R a, R q, R t$ and $R z$ ) for each method are presented in Table 1, with significant differences among the methods $(p<0.001)$. The results showed a more elevated values of all parameters in the $\mathrm{mF}$ method treated discs.

\begin{tabular}{|c|l|l|l|l|}
\hline \multicolumn{5}{|c|}{ Table 1. Mean and standard deviation of the surface profilometry values of the discs each method. } \\
\hline Method & $\operatorname{Rt}(\mu \mathrm{m})$ & $\mathrm{Rq}(\mu \mathrm{m})$ & $\operatorname{Ra}(\mu \mathrm{m})$ & $\mathrm{Rz}(\mu \mathrm{m})$ \\
\hline $\mathrm{mA}$ & $6.91 \pm 1.31$ & $0.80 \pm 0.16$ & $0.66 \pm 0.13$ & $5.94 \pm 0.40$ \\
\hline $\mathrm{mB}$ & $12.39 \pm 8.68$ & $0.99 \pm 0.07$ & $0.99 \pm 0.18$ & $5.14 \pm 1.01$ \\
\hline $\mathrm{mC}$ & $13.55 \pm 2.23$ & $1.03 \pm 0.17$ & $1.23 \pm 0.21$ & $5.25 \pm 0.79$ \\
\hline $\mathrm{mD}$ & $6.73 \pm 1.32$ & $0.84 \pm 0.08$ & $0.52 \pm 0.09$ & $4.32 \pm 0.62$ \\
\hline $\mathrm{mE}$ & $20.93 \pm 2.02$ & $4.82 \pm 0.99$ & $3.56 \pm 0.61$ & $7.59 \pm 1.77$ \\
\hline $\mathrm{mF}$ & $24.22 \pm 2.43$ & $5.77 \pm 1.09$ & $4.07 \pm 0.85$ & $10.98 \pm 2.43$ \\
\hline
\end{tabular}

\section{Cell viability analysis:}

To evaluate the influence of different surfaces in the growth of cells, a fibloblast like cell line was used in an in vitro experiment where, after cultured for 24 hours, fibroblast mithocondrial activity was evaluated through MTT assay. Figure 4 shows significant higher mitochondria activity levels of cells growing on titanium discs treated with $\mathrm{mF}$ method.

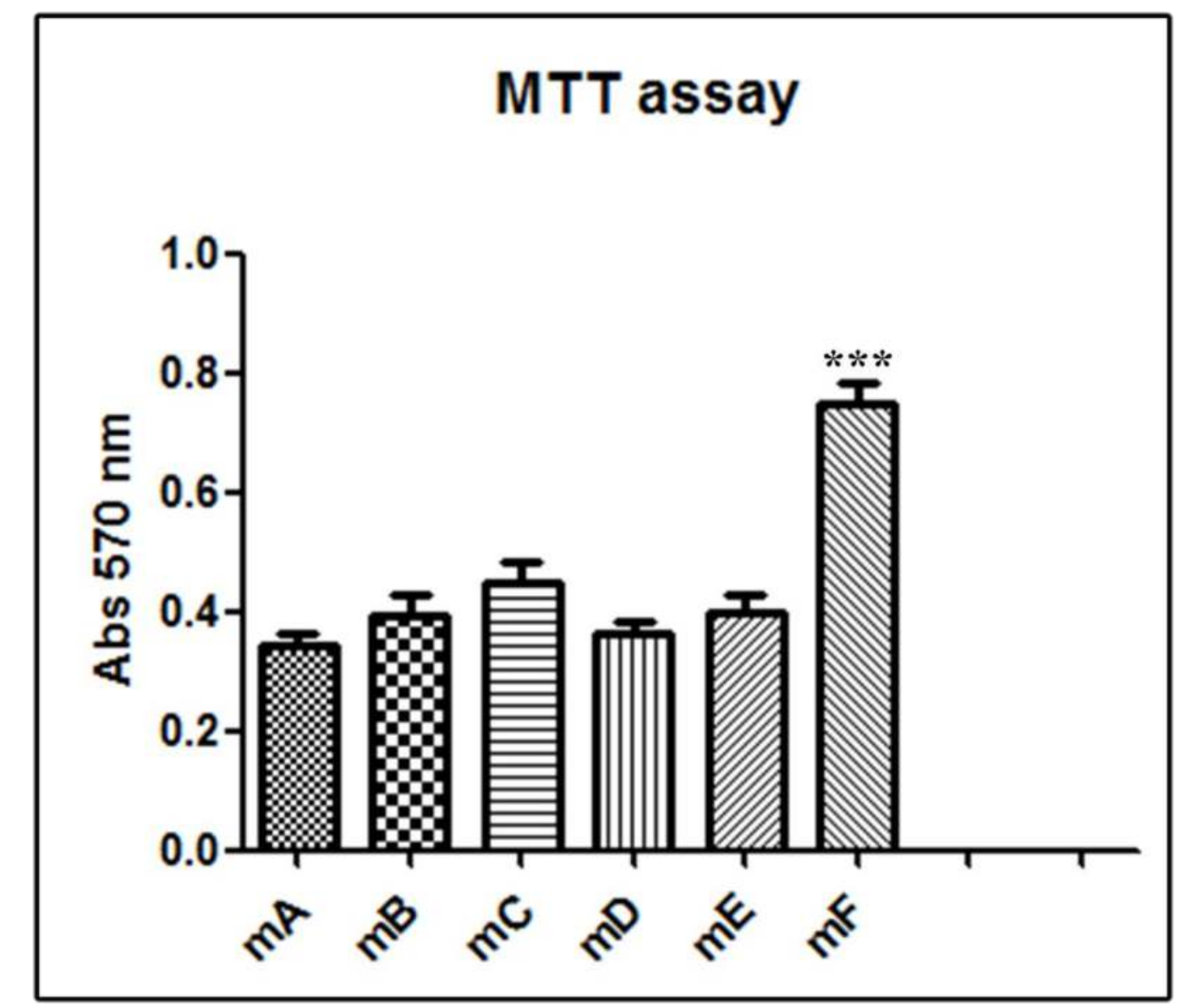

\section{Conclusions}

In conclusion, titanium discs manufactured with method $\mathrm{mF}$ resulted the best surface for in vitro fibroblasts growth, since more cell viability was observed in $\mathrm{mF}$ surfaces in comparison to the other conventional tested surfaces. Furthermore, the observations showed that the rugosity parameters variations not affect and/or stimulates the fibroblasts cell growth, but the morphologic characteristics (spherical form) increase substantially the fibroblasts cells growth over these protuberances.

\section{References}

1. Hamilton DW, Chehroudi B, Brunette DM. Comparative response of epithelial cells and osteoblasts to microfabricated tapered pit topographies in vitro and in vivo. Biomaterials. 2007.

2. Rompen E, Domken O, Degidi M, Pontes AEF, Piattelli A. The effect of material characteristics, of surface topography and of implant components and connections on soft tissue integration: a literature review. Clinical Ora Implants Research. 2006

3. Eisenbarth E, Velten D, Schenk-Meuser K, Linez P, Biehl V, Duschner H, Breme J, Hildebrand $H$. Interactions between cells and titanium surfaces. Biomolecular Engineering. 2002 